\title{
The Role of Interpretation in Fostering the Psychotherapy Process: Evidence from a Single
}

\section{Case Study}

\author{
Alessandro Gennaro ${ }^{1}$, Diego Rocco ${ }^{2}$, Attà Negri $^{3}$, Andrea Auletta ${ }^{4}$, Tiziana Marinaci ${ }^{5}$, Gaia \\ Dell'Arciprete $^{2}$, Skaiste Gabriele Kerusauskaite ${ }^{1}$, Sergio Salvatore ${ }^{1}$
}

\begin{abstract}
1 Department of Dynamic, Clinical psychology and Health Studies, "La Sapienza” University of Rome
2 Department of Developmental and Social Psychology, University of Padua

3 Department of Human and Social Sciences, University of Bergamo

4 Center for Addiction, National Health Service Rm2, Rome

5 Department of History Society and Human Studies; University of Salento
\end{abstract}

\begin{abstract}
The role of interpretation as a core intervention promoting good outcomes in psychotherapy is well acknowledged and established. Nevertheless, evidence of the role of interpretative interventions in promoting patients' change dynamic is still lacking. The present work, a good outcome psychotherapy single case study, focuses on how different interpretative modalities support different patients' intrapsychic dynamics implied in changing affective experience interpretation and clinical success. The grid of the models of interpretation (GMI) and the Discourse Attributes Analysis Program (DAAP) were applied to all therapy transcripts $(\mathrm{N}=76$ sessions $)$ in order to detect, respectively, the interpretative models enacted by the therapist and patients' intrapsychic processes subtending affects elaboration. Two different regression models tested the role of interpretative interventions in promoting specific processes supporting patients' affective elaboration. A further regression model then highlighted a specific configuration in the clinical course in processes promoting affect elaboration. Results are discussed, offering cues for a clearer understanding of the role of the therapist's interpretative interventions in promoting the clinical dynamics, thereby paving the way for the change process.
\end{abstract}

Keywords: psychotherapy, change process, interpretation, referential process, affects, GMI, clinical techniques 


\section{The Role of Interpretation in Fostering the Psychotherapy Process: Evidence from a Single}

\section{Case Study}

Within psychoanalytic and psychodynamic approaches, interpretations have been considered as core interventions, helping clients to find new explanations, perspectives, and frameworks for the concerns they face (Crits-Christoph et al., 2013; Frank \& Frank, 1991; Gazzola \& Stalikas, 2004). Clinical tradition offered insightful understanding on how interpretations foster change in individuals' inner experience (Wolf, 1993) and, as stated by Lachmann and Beebe (1993), interpretative interventions promote access to affects, which represents an important aspect of the transformative process. As an example, Bateman and Holmes (1995) suggest that interpretative interventions enable patients to widen the endopsychic perceptual field (Rycroft, 1968), allowing them to make sense of the incomprehensible, to find meaning where there seemed not to be any, and to open to new affective experience. Gabbard $(2005,2009)$ highlights that interpretative work has an explicative role: it consists of making conscious to the patient what was previously unconscious, and, in so doing, modifying those representations and the associated affects which shape patients' perception and interpretation of current experiences. Caligor and colleagues (2009) argue that the interpretative process focuses on dissociated aspects of experience that are either accessible to consciousness, though at different times, or are enacted by the patient without being consciously experienced or mentally represented. Thus, interpretations enhance affect regulation and decrease splitting, leading to a progressive integration of experience. Similarly, Kernberg and colleagues (2008) suggest that interpretative interventions lead to an integration of the split-off idealized and persecutory segments of experience, ultimately helping the patient to achieve a coherent sense of self and others. Higa and Gedo (2012) argue that interpretation clarifies to patients the reasons that object representations have been split off, and this uncovering process leads to the integration of affects and representation of the patient's self and others (Levy et al., 2006). Voutilainen and colleagues (2010) highlight that interpretative interventions point to something that is implicit in patients' experience, 
offering them a new angle or connection to consider their experiences in order to distance themselves from their own description of the experience. Even in parent-child treatments (Pitillas, 2020), interpretative interventions are seen as the endpoint of a clinical dialogue directed at promoting the working through of conflicts.

On the other side, empirical research traditions have focused on the effects (i.e., the outcomes) and the conditions (i.e., the processes) supporting interpretations' effectiveness. McCullough and colleagues (1991) highlighted that transference interpretations, if not followed by patients' defensive response, favor good outcomes, and that patients' response to transference interpretations strongly depends on the quality of their own object relations (Winston et al., 1993). Hersoug and colleagues (2014) evidenced that transference interpretations promote positive effects on long-term functioning in patients with low quality object relations. Bond et al. (1998) highlighted that a strong clinical alliance creates a safe environment in which transference interpretation works efficaciously; similarly, Hill and colleagues (2020) highlighted that the efficacy of interpretative interventions in facilitating patients' insight strongly depends on their level of collaboration. Considering the role of transference interpretations in promoting outcomes, research results have reported negative correlations in some specific conditions (Brumberg \& Gumz, 2012; Connolly et al., 1999; Høglend, 2004; Høglend and colleagues 2008; Ogrodniczuk \& Piper, 1999; Piper et al., 1991, 1993, 1998, 1999). As shown by Schut and colleagues (2005), persisting in transference interpretation can lead to the onset of hostile interactions with patients, which in turn affect clinical outcomes. In contrast, Høglend and colleagues (2008), assessing the long-term effects of transference interpretations in brief dynamic psychotherapy, highlighted that interpretative interventions sustained improvement of the patient's relationships outside therapy, especially for patients with long-standing, more severe interpersonal problems.

In sum, clinical tradition has increased knowledge about the role of interpretative techniques in enriching patients' access to warded-off affects, relying on a basic assumption by which interpretation promotes affect elaboration. Nevertheless, it has not yet been deepened how such a result is gained- 
namely, how the goal summarized by Freud in the sentence "where id was, there ego shall be" (Freud, 1932/1973, p. 4688) is reached. The empirical research tradition has focused on the impact of interpretative interventions on clinical processes and outcomes, but mostly on transference interpretations, which represent only one among the other interpretative techniques (see Gabbard, 2009): it has not offered a clear view on how different interpretative interventions influence patients' processes of affect elaboration.

Up to now, it is not clear how the different modalities of interpretative interventions support change in the elaboration of affective experience: interpretative interventions change over the course of therapy, and so the interpretations displayed by the same therapist at two different moments will not have the same features in terms of focus, form, timing, etc. In light of their specificity, the interpretations foster different processes of affect elaboration.

The need to face this issue is not new in research and the clinical field: as Bateman and Holmes (1995) highlighted, the theoretical aims of interpretations are clear, but in practice, the forms, timings, and kinds of interpretation, which are very important in determining their impact, are not defined. Caspar and colleagues (2000) suggest that to further investigate which characteristics of the clinical process are influenced by interpretative interventions, we need to focus on the modalities through which the interpretative process is carried on. On this basis, it is possible to sharpen the understanding of how therapists' interpretations take effect, or fail to take effect, in the context of a particular dyad. Similarly, the need to distinguish among the different foci of interpretative interventions to improve knowledge about their role in fostering clinical success has been argued even in parent-child therapy (Baradon et al., 2016; Pitillas, 2020).

According to such considerations, the present study aims to contribute to bridging the clinical and empirical research traditions. Through a single case study, we aim to shed light on how different interpretative modalities promote specific processes of affect elaboration, promoting patients' change process. Moreover, we aim to describe how — according to the specificity of the case under analysisthe clinical process, in light of specific interpretative modalities, follows a specific pathway. This 
contribution could be considered relevant given that it allows a focus on how the specific modalities through which interpretative techniques are driven foster change in individuals' affective experience elaboration.

\section{Affects, Clinical Process, and Interpretative Processes}

Different clinical and theoretical approaches_metacognitive therapy (Dimaggio et al., 2020; Ogden \& Fisher, 2015), psychodynamic approaches (Gabbard \& Horowitz, 2009; Salvatore \& Freda, 2011), cognitive narrative intervention (Gonçalves \& Machado, 1999); emotion-focused therapy (Diener et al., 2007; Greenberg, 2004, 2021), schema therapy (Leahy, 2019), and many othersconsider affects as basic processes shaping individuals' life experience. Affects offer a fast and frugal appraisal (Gigerenzer \& Goldstein, 1996), triggering and orienting cognitive processing (Asutay et al., 2020; Barrett, 2017, 2020; Damasio, 2010; Muramatsu \& Hanoch, 2005) which, in turn, organizes individuals' life experience in terms of representations, cognitive schemas, relational strategies, behavioral patterns, coping strategies, beliefs, expectations from others, conceptions about self, and so forth (Faustino \& Vasco, 2020; Gennaro et al., 2011; Gross, 2015; Pascual-Leone \& Greenberg, 2007). In this perspective, maladaptive functioning, interpersonal problems, and individuals' distress could be due to individuals' affective appraisal, which makes their life experience organization unable or dysfunctional in managing and addressing environmental patterns (Morris \& Mansell, 2018; Venuleo et al., 2020).

The goal of clinical intervention may be conceived as the promotion of patients' development of new and/or different modalities to affectively appraise experience which, in turn, foster more functional ways to face the life experience (Gennaro et al., 2017; Morris \& Mansell, 2018; Rocco et al., 2017). Through clinical speech, patients actualize in the psychotherapy setting their own (in)effective modalities to organize experience and clinical interventions (Bucci \& Cornell, 2020; Greenberg \& Safran, 1989; Moltrecht et al., 2020; Stern, 1997); in this context, the clinical exchange aims to improve patients' access to their own affective appraisal (Greenberg, 2007, 2021; Lecours et 
al., 2010) as a way to elaborate affective experience and, ultimately, to set in motion new or more adaptive modalities and operative patterns to organize and face life experiences.

Access to affects is promoted, among other techniques, by therapists' interpretations (Aron, 1996; Bucci \& Cornell, 2020; Etchegoyen, 2005; Kernberg et al., 2008; Levy \& Scala, 2012; Silberschatz et al., 1986), which represent cross-theoretical constructs (Ahn \& Wampold, 2001; Barkham \& Shapiro, 1986; Gazzola \& Stalikas, 2004; Gelso et al., 2012; Gibbons et al., 2002; Gilbert \& Leahy, 2007; Spiegal \& Hill, 1989; Wiser \& Goldfried, 1996) that enable the revision of patients' own affective appraisal, and support the elaboration of an (at least partially) different affective positioning toward their life experience (Atwood, \& Stolorow, 1984; Stolorow, 2002; Stolorow \& Atwood, 1984; Summers, 2005).

The impact of interpretations on affective elaboration is recognized by several streams of psychodynamic thought. Strachey (1937), for example, suggests that mutative interpretations work according to two different stages: they increase patients' awareness of their own affects directed toward the analyst and then enable them to distinguish between the analyst and the transferred archaic object. Bateman and Fonagy (2013) highlight the role of interpretative interventions in increasing patients' self-reflective function, which promotes perceptions of their own and others' behavior as the results of internal intentional states. Modell $(1984,1986)$ emphasizes the role played by the therapeutic relationship, defining the interpretation as a transactional act that cannot be separated from the nature of the relationship between patient and therapist at the exact moment the interpretation is made.

Effective interpretations weaken the pressure of active affective appraisal on individual modalities to organize experience. In so doing, interpretations enable individuals' ways to organize experience to reassemble themselves in new ways, leading to new modes of attributing meaning to experience, to behave, and to develop new configurations of the self (Levy et al., 2006; Levy \& Scala, 2012; Stolorow, 1997; Stolorow \& Atwood, 1992). In sum, interpretative interventions, by enriching and modifying the affective experience of lived experiences, provide opportunities for patients to 
issue new and more functional operative patterns, letting novel interests, desires, wishes, and ambitions emerge (Caligor et al., 2009; Joseph, 1992; Steiner, 1996; Stern, 1997, 2004; Stolorow et al., 1987; Summers, 2001, 2005; Summers \& Barber, 2010).

Clinical experience suggests that such an effect could be achieved through different interpretative modalities. Interpretative interventions could support patients in engaging specific affects and representation warded off from psychic life, as in the case of "interpreting up" interpretative interventions (see Busch, 2000; McWilliams, 1994, 1998; Ridenour, 2016)—namely, interpretative modalities going right to the heart of the concern, naming the content and providing an explanation of why the material would have been activated by the patient's life experiences. Differently, interpretative interventions could support patients' affective regulation and affects management, as in the case of "interpreting down" (see Busch, 2000; McWilliams, 1998; Ridenour, 2016) - namely, those interpretative interventions mainly focused on addressing whatever defense is close to conscious understanding, to let the patients increase their own ability to self-discover and manage warded off affects, as well as improve autonomous ego functioning, reality testing, and adaptation.

According to the research aims, we hypothesize that different interpretative modalities support different processes of affects elaboration. Specifically, in hypothesis 1 (H1: Effects of the interpretations) we expect that specific interpretative modalities will sustain different patients' elaborative processes aimed respectively at increasing patients' affect experiencing and enriching the connection between affect experiencing and its cognitive processing. Moreover, in hypothesis 2 (H2: Clinical process functioning), according to clinical literature concerning treatments with schizoid personality traits (see Coen, 2003, 2005; Wheeler, 2013; and case description), through the whole clinical process change is expected to be accomplished by means of a specific configuration: increasing patients' access to warded off affect represents a preliminary step which should allow patients to face cognitive processing of their own affective experience in a non-defensive way, ultimately improving adaptation. 
Testing these hypotheses will promote a clearer comprehension of the role of interpretative interventions in affecting patients' functioning, thereby shedding light on the role of a widely acknowledged technique supportive of the clinical outcome and change and offering cues to therapists for in-session case management.

\section{Method}

\section{Case Description}

We have analyzed all 76 sessions belonging to a good outcome psychotherapy: Max's case (Gennaro et al., 2017). Max was a self-referred 35-year-old Italian male presenting relational problems with his wife and his birth family. He reported a strong relationship detachment from people belonging to his life, accompanied by the sensation of being criticized by his wife and his mother. In response to these sensations, the patient demonstrated a withdrawal strategy and passive-aggressive defense mechanisms. Max avoided sharing his feelings, thoughts, or life events with other people (for instance, in the work environment), experiencing a solitary relational situation as a result. According to the Shedler-Westen Assessment Procedure-200 (SWAP-200; Westen \& Shedler, 1999a, 1999b), Max was diagnosed with a schizoid personality disorder (SWAP-200 PD values over the threshold value of 60), with both avoidant and obsessive traits (SWAP-200 PD values between 55 and 60) inscribed in a high-functioning global structure. He received a weekly psychoanalytically-oriented therapy for two years (74 sessions followed by two follow-up sessions four months later). The therapist was a male clinician with more than ten years of experience in psychoanalytically-oriented treatment. In accordance with the SWAP-200 and the core conflictual relationship theme method (CCRT; Luborsky et al., 1994), both applied by independent judges, the treatment was considered a good outcome. For both methods, judges reached an excellent level of overall agreement (Cohen's $K$ > .85; see Fleiss, 1981; Fleiss \& Cohen, 1973; Shrout \& Fleiss, 1979). Specifically, the CCRT showed significant changes between pre- and post-treatment (see Table 1) in two out of three CCRT components: response from others and response from self. The wishes component did not show significant changes, which is consistent with the literature that acknowledges it is less sensitive to 
clinical change (Luborsky \& Crits-Christoph, 1990). Pre- and post-treatment differences in the CCRT formulations highlighted specific changes: at the beginning of the treatment, the patient perceived other people as opposing him and, for that reason, he felt depressed and ashamed; at the end of treatment, he felt appreciated by others, as well as respected and able to accept himself. Moreover, consistent with the CCRT evaluation, comparison between the pre- and post-treatment applications of the SWAP-200 showed a decrease below the clinical relevance threshold of scores in schizoid, obsessive, and avoidant traits. In sum, the patient's changes in relational themes were supported by a less pervasive use of defense mechanisms usually adopted to manage his psychological distress.

\section{INSERT TABLE 1 ABOUT HERE}

\section{INSERT TABLE 2 ABOUT HERE}

\section{Measures and Procedures}

In order to test the hypotheses concerning the role of clinical interpretations in triggering specific processes of affect elaboration, the following measures have been applied: the grid of the models of interpretation (GMI), a category system aimed at detecting therapist interpretations and qualitatively analyzing the interpretative work performed by therapists (Auletta \& Salvatore, 2009; Auletta et al., 2012), and computerized linguistic measures of the referential process, as performed by the Italian Discourse Attributes Analysis Program (IDAAP), a program able to detect emotional engagement and its cognitive elaboration in narrative production (Mariani et al., 2013; Maskit, 2014c; Maskit \& Murphy, 2011; Negri et al., 2018; Negri \& Ongis, 2021).

Both the adopted measures are transcript-based and are reliable trans-theoretical instruments (Auletta et al., 2012; Bucci, 2011; Mariani et al., 2013), widely acknowledged as markers of the clinical process (Auletta \& Salvatore, 2009; Auletta et al., 2012; Negri et al., 2019; Rocco et al., 2017; Schut et al., 2005). 


\section{Identification of Interpretative Interventions}

The GMI (Auletta \& Salvatore, 2009; Auletta et al., 2012) identifies the interpretative interventions in clinical sessions and categorizes them according to qualitative similarities. The GMI's reliability has been tested according to both psychodynamic and cognitive therapies. It evaluates the therapist's interpretative interventions according to five different qualitative variables, called dimensions, which are measured on a nominal (categorical) scale. In line with the literature (Chambers \& Bickhard, 2007; Gazzola \& Stalikas, 2004; Salvatore \& Freda, 2011; Salvatore et al., 2010), the GMI operatively defines the interpretative intervention as "a therapist statement where an innovative meaning is suggested as regards the patient's current framework, where [the] patient's framework is intended as the system of assumptions grounding, constraining and regulating the speaker's way of thinking" (Auletta \& Salvatore, 2009, p. 66). Each interpretative intervention is evaluated according to 17 mutually exclusive variables that define the following five dimensions qualitatively describing interpretations (a full description of the dimensions and the categories is given in Table 3): the content dimension pertains to the interpretative issue (representations, defense mechanisms, motives, general way of functioning, drives, or affects) beyond the self, the therapist or other people, and it does not pertain to the past or present moment (such aspects are described through further dimensions); the domain dimension distinguishes whether the interpretation concerns the patient's interpersonal (if it implies the therapist or other people) or intrapsychic life; the time orientation dimension pertains to the temporal reference of the therapist's interpretation, with two categories concerning discrete temporal references (past, present) and two categories concerning the directions of their connection (past-to-present and present-to-past); the dichotomous space frame dimension distinguishes between two interpretative focuses, regardless of their temporal referencethat is, the patient's experience concerning the therapeutic situation (internal) and the experience outside therapy (external); lastly, the style dimension refers to the therapist's modalities of delivering the interpretation and includes three mutually exclusive categories: interpretations can be presented as descriptions of facts, personal beliefs, or something that must be demonstrated. 


\section{INSERT TABLE 3 ABOUT HERE}

Identification of sessions' interpretative characteristics. Five judges, two females and three males, rated the session transcripts according to the GMI. Raters were clinical psychologists or experienced psychotherapists with competences in clinical research methods, who underwent about 30 hours of training on the identification of interpretative interventions and application of the GMI category system. Cohen's kappa values (Cohen, 1960; Fleiss, 1971) were calculated among raters to detect the degree of interrater agreement concerning both identification of the interpretative intervention $(K=.75)$ and application of the category system ( $K$ ranged from 0.61 to 0.81 according to the category). According to Landis and Koch (1977), the mean $K$ values exceed the threshold of substantial and almost perfect agreement (for details on GMI reliability, see Auletta et al., 2012).

Once the GMI had been applied, a multiple correspondence analysis procedure (MCA; Benzécri, 1973, 1979) was applied on the matrix, having interpretations as rows and the 17 categories as columns. Each category belonging to the same dimension was treated as a dichotomous variablethat is, cell $\mathrm{ij}$ could assume two values: 1 if the $\mathrm{j}_{\text {th }}$ category marked the $\mathrm{i}_{\mathrm{th}}$ interpretation, 0 otherwise. Factors extracted by the MCA allowed a description of the interpretative modalities enacted by the therapist according to GMI categories.

Lastly, for each session, the mean of the cosine value for each retrieved factor was calculated. The cosine value represents the degree of association of each interpretative intervention with the extracted factors (Child, 2006); thus, a session's cosine arithmetical mean offers a description of the session's interpretative characterization in light of the specific retrieved interpretative factors. Such a choice allowed us to gain a description of each session according to a multidimensional interpretative plan in which, for each session, the higher the cosine value of a factor, the higher the session's interpretative activity described by the factor.

\section{Patient's processes of affects elaboration}


To detect patients' processes promoting affects elaboration, clinical transcripts were analyzed through the IDAAP, a validated computerized linguistic analysis method (Bucci \& Cornell, 2020; Mariani et al., 2013; Maskit, 2014a; Maskit \& Murphy, 2011; Negri et al., 2018). The IDAAP detects the processes of emotional activation and cognitive reorganization in clinical sessions (Bucci \& Maskit, 2006; Bucci \& McKay, 2014; Maskit, 2014a), analyzing narratives according to word lists called dictionaries (see Maskit, 2012; Maskit \& Murphy, 2011). The main IDAAP dictionaries are the following: the Italian Weighted Referential Activity Dictionary (IWRAD), the Italian Weighted Reflection and Reorganization List (IWRRL), and the Italian Reflection-related Words Dictionary (IRefD).

For each analyzed text, application of the IWRAD provides the average of the weights that the words assume in terms of referential activity (RA; Mariani et al., 2013). The RA ranges from 0 (lowest) to 1 (highest) and represents the degree to which a speaker is able to translate his own emotional, visceral, and relational experience into words and evoke corresponding experiences in the listener or the reader (Bucci, 2011). The IWRAD analyzes the connection between words and emotional experiences, and is considered a measure of emotional involvement.

The IWRRL is composed of words associated with the reflection and reorganization function. It ranges from 0 (lowest) to 1 (highest) and measures the degree to which the speaker is trying to recognize and reorganize the personal emotional meaning of memories, fantasies, dreams, or events in his own or someone else's life. The IWRRL is considered an index of the personal elaboration of emotional experiences (Bucci et al., 2016; Mariani et al., 2013; Negri et al, 2018; Negri, Andreoli, Mariani, et al., 2020; Zhou et al., 2021).

The IRefD, an index ranging from 0 (lowest) to 1 (highest), provides the proportion of words in a text referring to cognitive or logical functions or communication processes that imply the use of cognitive functions (Bucci et al., 2016; Mariani et al., 2013).

For any pair of dictionaries, the IDAAP software produces a set of measures called covariations (Bucci \& Maskit, 2007), able to detect the extent to which two dictionaries move together or in 
different directions. Covariations among the dictionaries are closely related to the (Pearson) correlation coefficient, but, due to the DAAP procedure, dictionaries values are not statistically independent $^{1}$ (for details on the procedure, see Maskit, 2014b, 2014c). Nevertheless, as for correlation coefficient, the covariation varies between -1 and +1 .

IWRRL_IWRAD covariation highlights the extent to which a speaker is emotionally engaged in describing an image or telling a story and, at the same time, in finding a personal meaning in the story (Maskit, 2021; Negri et al., 2018). Negative covariations highlight specific patients' narrative modalities: the patient speaks about their own emotional experience in a concrete and vivid way (high IWRAD) without accounting for specific personal meanings in their narrative (low IWRRL); conversely, the patient could reflect on their own emotional experience (high IWRRL) without significant emotional involvement in the story (low IWRAD). Positive covariations highlight narrative modalities characterized by patients' ability to be engaged affectively in telling a story (high IWRAD) and recognize personal meanings in the emotional experience with immediacy and vividness (high IWRRL). For example, let us imagine that after a clinician's interpretation, the patient says: "Now I understand... When my boss calls me into her office, I feel afraid and sick, I feel shivers down my body... Uhm... I feel the same sensation I was feeling when my mother was calling me in the kitchen after I did something wrong to bollock me.” In this example, the patient shows an ability to focus on their own affective state and to fit a personal meaning to such experience. In other words,

\footnotetext{
${ }^{1}$ The DAAP procedure mathematically smooths the relative usage of words for each dictionary according to the analyzed segment (e.g., change of speaker, sentences, or sessions, and so on). The smoothing procedure consists of two steps: a weighted moving average and a wrap-around procedure. At each word, the weighted moving average uses the dictionary value of the word itself, along with the dictionary values of both the preceding 99 words and the following 99 words. This procedure causes some difficulties with the first and last 99 words of each segment. The wrap-around procedure faces this difficulty, allowing the dictionary to extend values to all words. Thus, for two considered dictionaries (e.g., A and $\mathrm{B})$, the neutral value is the mean of the dictionary values. The relationship between A and B dictionaries is then computed in terms of covariation. While, from the point of view of computation, the covariation is indistinguishable from the (Pearson) correlation coefficient, from a statistical point of view they are quite different. The correlation coefficient requires the individual items in $\mathrm{A}$ and $\mathrm{B}$ to be statistically independent, as test scores on the same test for two distinct groups of people. In our case, the values for both A and B for nearby words are not statistically independent since the smoothing operator takes nearby words into account.
} 
a positive IWRRL_IWRAD covariation characterizes those clinical interventions which allow patients to engage in an ongoing affective experience, sustaining a reorganization of the experience in order to favor comprehension of its meaning. Thus, increasing trends in IWRD_IWRRL covariation have been adopted as a proxy for patients' increased ability to engage, elaborate, and connect their own experiences, acknowledging their affective meaning and valence. Thus, it has been adopted as a proxy for individuals' ability to connect personal meaning to affective experience.

Such a view is supported by different research works. Recently Negri and colleagues (2020), analyzing the effects of expressive writing during the COVID 19 pandemic, adopted IWRAD_IWRRL covariation as a proxy for respondents' ability to get more in touch with the intense emotions that were experienced following the upheavals they witnessed. In their work, they highlighted that a respondent who had at least one COVID-19 patient among their close friends or relatives showed an intense emotional involvement together with an ability to reflect on and reorganize the personal meaning of the events and emotions experienced. Similarly, Renzi and colleagues (2020) adopted IWRAD_IWRRL covariation to evaluate patients' ability to connect affective and reflexive experiences in their stories. In their work, comparing the narrative production of patients diagnosed as high vs low alexithymic functioning, they highlighted that the higher the alexithymic functioning, the lower and more negative the covariation among these indices. Finally, Negri and Ongis (2021) assessed the ability of IWRAD_IWRRL to detect the extent to which the speaker is emotionally engaged in describing an image or telling a story and finding a personal meaning in this story. In their work, they explored the effects of colored object relations technique (Phillipson, 1955) cards on IWRAD_IWRRL covariation; in line with the affect color hypotheses (Exner, 2003; Silva \& Ferreira, 2014), they highlighted that the greater the chromatic features of the cards - an affect-eliciting characteristic — the more such covariation increases.

The IWRAD_IREF covariation is a measure of the extent to which a speaker is affectively involved in the narrative (IWRAD) and reflects on it (IREF). Positive IWRAD_IREF covariations describe attempts to keep a distance from the emotional experience through intellectualizing; in 
contrast, negative covariations highlight the speaker's ability to be affectively engaged and reflect on the narrated experience through non-defensive distancing modalities (Bucci \& Maskit, 2007). As Mariani and colleagues stated (2013), when the speaker is immersed in telling a memory or fantasy or dream, IWRAD is high and IREF is low; at a different time, the speaker may step back to look at the narrated events, focusing on their own role and position in them: then IREF will be high and IWRAD will be low.

As an example, let us imagine that after a clinician's interpretations, the patient says: "Yes, uhm... now effectively I remember that situation .... when my boss called me into her office and... I started to be afraid, I felt anxious, upset, and my heartbeat increased, I was sweating... Now that I think about it, I think she behaved like my mother did when I was a child... a very problematic relationship... she was unpredictable and I was always waiting for a negative judgment on me, no matter what I did." Such an example is characterized by a first step in which the patient is highly focused on their own affective state without reflecting on it (high IWRAD and low IREF), and a second step in which the patient finds a cognitive insight about the experience previously described (low IWRAD and high IREF).

Thus, decreasing trends in IWRAD_IREF covariation detect patients' increased ability to focus on affective experiences, managing and reorganizing them in a non-distancing or defensive manner. Accordingly, such an index has been adopted as a proxy for individuals' ability to cognitively process their own affective engagement. Different research works support such understanding: through the analysis of clinical sessions (Christian et al., 2021; Mariani et al., 2013) and analyzing the transcripts of clinical notes (Mariani \& Negri, 2015; Negri et al. 2019), the presence of a negative IWRAD_IREF covariation on the clinical course has been highlighted as an important predictor of good outcome and alliance. Lo Verde and colleagues (2012), focusing on the trend of IWRAD_IREF covariation, highlighted an overall decreasing trend which was consistent with results gained in the same case study by the therapeutic cycle model (Mergenthaler, 1996). Lastly, Mariani and Hoffman (2021), studying a long-term psychotherapy course, found that a negative IREF_IWRAD covariation and its 
overall decreasing trend-i.e., the alternation of high emotional immersion with logical, abstract language — could be adopted as an index of the success of a therapeutic/analytic process.

\section{Data Analysis}

The present work assumes the clinical process as a continuum unfolding through time, in which observed events cannot be assumed as independent from one another but rather as small changes deeply influencing forthcoming events (see Gennaro, 2011; Haken \& Schiepek, 2010; Hayes et al., 2007; Salvatore et al., 2010; Schöller et al., 2018; Tschacher \& Ramseyer, 2009). For this reason, change needs to be modeled in terms of phases or trends alternation. Such a view is not new in clinical process research: different works have modeled the process of change as it unfolded in the clinical process (e.g., Bucci, 2021; Gennaro et al., 2016; Gonçalves et al., 2009; Hill \& Lambert, 2004; Nitti et al., 2010; Rocco et al., 2017, 2018; Salvatore et al., 2010; Schiepek et al., 2016, 2018), pointing out the usefulness of describing the process in terms of trends from both the clinical and the research standpoint.

In line with such a view, measures adopted to detect individuals' processes of engaging and reorganizing affects (IWRAD_WRRL and IWRAD_IREF, respectively) in clinical speech have been considered according to a cumulative sum (CUSUM) data analysis procedure (Page, 1954). CUSUM charts have been widely adopted to shape processes in quality analysis in clinical and social science (see Millsap et al., 2016; Woodall, 2006), are acknowledged for their ability to detect small changes and shifts in process parameters (Lu \& Reynolds, 2001; Pignatiello \& Runger, 1990), and are recommended for longitudinal analyses (McCulloh \& Carley, 2011).

To detect trends in both IWRAD_IWRRL and IWRAD_IREF covariations, we calculated their CUSUM values for each session by adding the difference between the current values and mean to the previous sum, $S_{\mathrm{i}}=S_{\mathrm{i}-1}+\left(X_{\mathrm{i}}-\underline{X}\right)$ for $\mathrm{i}=1$ to $n$, where $S$ is the cumulative sum, $X_{\mathrm{i}}$ is the current value, and $\underline{X}$ is the mean. 
To identify the phases characterizing the clinical process, we plotted the CUSUM values for both the indexes and identified their trends according to the three highest and lowest CUSUM values, after which an inverse shift in the trend could be observed. On the basis of the increasing and decreasing trends identified, clinical sessions were labeled according to a dummy variable identifying the specific phase.

Considering H1 (i.e., effects of interpretations), two different logistic regression models were run to test how the interpretative modalities act in increasing patients' IWRAD_IWRRL trends—-that is, detecting access to one's own emotional experiences and acknowledgment of their affective meaning and valence — and promote a decrease in IWRAD_IREF trends_ — that is, detecting patients' ability to manage and reorganize a previous emotional engagement. Each model had the cosine values of the identified interpretative factors in each session as independent variables, and the identified dummy variable detecting the allocation of sessions to the increasing or decreasing trend as the dependent variable.

Regarding H2 (i.e., clinical process functioning), a linear regression model was run to test the presence of a specific configuration subtending affect elaboration, having IWRAD_IWRRL as the dependent variable and IWRAD_IREF as the independent variable. In so doing, we tested the role of patients' engaging warded off affect as a basic process promoting the focus, reorganization, and management of affects in a non-defensive manner.

\section{Results}

The application of the MCA to the GMI allowed us to retrieve five factorial dimensions as an optimal partition (cumulative inertia - i.e., variance $-87.5 \%$, see Table 4 ) which, considering the high dispersion of the data in the matrix under analysis, represents a high percentage of explained variance with respect to the fact that the rate of variance depends on the number of categories under analysis (see Benzécri, 1973, 1979; Bolasco, 1999). Factors were labelled as follows: Factor 1 general models of interpretation: interpretative interventions focused on events happening inside or 
outside the sessions; Factor 2 - affective state interpretations: interpretative interventions focusing on patients' inner affective states; Factor 3 - situated interpretations: interpretative interventions focused on the relationship between affects and behavior; Factor 4 - subjective interpretations: interpretative interventions through which the therapist communicates his or her own viewpoint; Factor 5 -transference interpretations: interpretative interventions focused on the relationship with the patient during the session.

\section{INSERT TABLE 4 ABOUT HERE}

CUSUM data analysis on IWRAD_IWRRL and IWRAD_IREF allowed to identify a change point in session 19, session 33, and session 54 for IWRAD_IWRRL trends, and in session 28, session 46, and session 69 for IWRAD_IREF trends (see Figure 1). According to such trends, sessions were dummied into decreasing and increasing trends (see Table 5).

\section{INSERT FIGURE 1 ABOUT HERE}

\section{INSERT TABLE 5 ABOUT HERE}

The logistic binary regression model testing the role of interpretation in predicting the increase in patients' process of affective engagement (IWRAD_IWRRL) showed statistically significant results $\left(\chi^{2}=14.290, d f=5, p=.014\right.$, Negelkerke $\left.\mathrm{R}^{2}=.231\right)$; the concordant association of predicted probabilities and observed responses was 69.7 percent. As shown in Table 6, three out of five factors showed a significant role in predicting an increase in IWRAD_IWRRL trends; specifically, although to different extents, interpretative factors 2, 3, and 4 assumed a significant role in supporting IWRAD_IWRRL.

Similarly, the logistic binary regression model testing the role of interpretative factors in promoting decreasing IWRAD_IREF showed statistically significant results $\left(\chi^{2}=15.704, d f=5, p=\right.$ 
.008 , Negelkerke $\mathrm{R}^{2}=.258$ ); the concordant association of predicted probabilities and observed responses was 68.4 percent. As reported in Table 7, the negative B highlights the role of interpretative factors 1 and 3 in supporting patients' management and reorganization of affects in a non-defensive way.

Lastly, the linear regression models testing the primacy of personal affect focusing and engagement (IWRAD_IWRRL) in supporting patients' ability to manage and reorganize affects in a non-defensive manner (IWRAD_IREF) offered insightful results (see H2): IWRAD_IREF covariation was meaningfully $(R=.544, F=20.614, P<.001)$ predicted by the IWRAD_IWRRL covariation $(B=.306, B$ std $=.544, p<.001)$.

\section{INSERT TABLE 6 ABOUT HERE}

\section{INSERT TABLE 7 ABOUT HERE}

\section{Discussion}

The present work highlights the role of interpretations in enabling patients to give meaning to their emotional experiences, thereby promoting individuals' relational modalities. On the whole, the outlined results fit previous clinical conceptualizations of the role of interpretations. Stolorow, for instance, stated that "effective interpretations are perturbations that disrupt the repetitive attractor states dominating the patient-analyst system, freeing its components to reassemble in new ways, establishing the possibility of alternative principles for organizing affectively experience" (Stolorow, 1997, p. 342).

As a first result (H1, effect of interpretative interventions), the proposed study highlights how specific interpretative modalities drive different patients' processes of affective elaboration. Patients' ability to connect with an affective experiencing process (expressed by an increase in IWRAD_IWRRL values), that allows them to make sense of previously warded off content, is 
promoted by clinical interpretative modalities focusing on patients' inner affective states (affective state interpretations), interpretative interventions focusing on the relationship between affects and behavior (situated interpretations), and interpretative interventions in which the therapist communicates his own viewpoint (subjective interpretations). Likewise, patients' process of connecting affects and cognition (decreasing IWRAD_IREF trend, detecting patients' cognitive processing of affects through non-defensive modalities) is favored by interpretative interventions focusing on events happening inside and outside the session (general model of interpretation) and interpretative interventions focusing on the relationship between affects and behavior (subjective interpretations).

The following clinical excerpt taken from session 46 (see Table 8) could help to understand how specific clinical interventions affect the elaboration process according to the outlined perspective.

\section{INSERT TABLE 8 ABOUT HERE}

This excerpt highlights how interpretative interventions promote patients' affective elaboration process (the excerpt shows positive (+0.28) IWRAD_IWRRL and negative $(-0.51)$ IWRAD_IREF values). Both therapist interventions (turn 152 and 154) are classified as instances of the positive pole of the third interpretative factor: situated interpretation. The therapist focuses on the patient's affect state, linking events belonging to the past with present issues, and the interventions are delivered in a demonstrating style (that is, by explaining how, offering examples, and reporting anecdotes). Clinical interventions connect the current feelings of anger and blockage that the patient feels toward his wife with the memory of similar feelings felt in the relationship with his mother during childhood. The patient's following intervention (turn 155) shows an effective elaborative process, which allows the patient to find a new-in part unexpected—personal meaning in his own experience, linking his past affective experience-feelings and sensations felt with his mother and father-to that 
experienced in the present toward his wife (IWRAD_IWRRL $=+0.91$ ). The same intervention exemplifies the sequential and productive passage from the vivid memory of concrete emotional sensations experienced in childhood (anger and isolation) to the more abstract and general meaning found in the current relational situation with his wife in connection with the past (identification with the father) (IWRAD_IREF $=-0.95)$.

As a further result ( $\mathrm{H} 2$, clinical process), the present study highlights how the investigated clinical processes follow a specific configuration: the enriched ability to engage and get in touch with inner warded off affects drives patients' processing of affects through non-defensive modalities. Such a configuration is fully consistent with the suggestion for treatment of schizoid personality organization. Schizoid personality organization is characterized by detachment from social relationships and a narrow range of emotional expressions in interpersonal situations, which limit patients' contact with their own emotional experience and that of others, considering their difficulties in reading both their own and others' emotions (Gabbard, 2007). Accordingly, the outlined interpretative configuration driving the clinical process is fully consistent with the recommended interpretative work with schizoid patients. As McWilliams (1994) suggests, clinicians in these cases should primarily "interpret up", to favor patients' understanding of their own experience; that is, clinicians should plumb the depths, name the content, and explain why that material would have been set off by the patient's life experiences: "By behaving in a way that conveys that the schizoid person's inner world is comprehensible, the therapist helps the client to take in the experience of being accepted" (McWilliams, 1994, pp. 238-239). The experience of inner comprehension allows schizoid patients to experience the feeling of being accepted, which allows the further clinical work focused on patients' affect managing (McWilliams, 1994). As in the case under analysis, this is conveyed by interpretative interventions focused on increasing abilities in self-discovering, managing warded off affects, improving autonomous ego functioning, reality testing, and adaptation. In short, the clinical interpretative work followed a specific configuration aimed firstly at supporting growth in the 
patient's understanding of his own affects driving life experience, and then at supporting the patient's management of affects to frame a different affective positioning in his individual life experience.

\section{Conclusion}

Consistent with research trends, this study aimed to shed light on how the clinical process works. The study switches the focus from the technique itself to the modality through which the technique is pursued and its role in affecting specific clinical processes. Despite the limitations of the present work - above all the single case study design, which prevents generalizability of the results to different cases, the focus on just one of all the possible techniques enacted by clinicians (the interpretative intervention), the lack of focus on mediator and/or moderator variables favoring or preventing interpretative intervention in supporting the change process, and so on - the present work offers several insights.

From a methodological point of view, the paper supports the importance of approaches that are not limited to measuring the size of the relationships among factors promoting the change process but also aim to model the mechanisms that ground such relations (Gennaro et al., 2017, 2020; Rocco et al., 2017; Salvatore et al., 2010; Salvatore \& Tschacher, 2012; Tschacher \& Ramseyer, 2009). Within such an approach, the current study provides: (a) a description of the specific role of interpretations in promoting different processes sustaining the change process; and (b) an empirically based description of the elaborative dynamics, activated by interpretative interventions, which pave the way for the change process.

From a clinical viewpoint, the study offers a clearer understanding of the specific role of interpretative interventions and highlights the need to further research the techniques themselves, in order to detect how they affect patients' elaboration dynamics. Moreover, the single case analysis design supports clinical and psychoanalytical literature (Coen, 2003, 2005; Gabbard, 2007; McWilliams, 1994), which has already stressed the importance of prioritizing specific kinds of interpretations with specific kinds of patient. 
Lastly, from an intervention management perspective, the research shifts the focus from the intervention itself to the specific modalities through which the intervention is pursued, highlighting the role of the interpretative technique in promoting change. From such a standpoint it underlines, above all, the usefulness of developing empirically-driven theories for cases and interventions management, thereby offering clinicians evidence of the suitability of the different modalities through which techniques are provided. 


\section{References}

Ahn, H. N., \& Wampold, B. E. (2001). Where oh where are the specific ingredients? A metaanalysis of component studies in counseling and psychotherapy. Journal of Counseling Psychology, 48(3), 251-257. https://doi.org/10.1037/0022-0167.48.3.251

Aron, L. (1996). A meeting of minds: Mutuality in psychoanalysis. Analytic Press.

Asutay, E., Genevsky, A., Hamilton, J. P., \& Västfjäll, D. (2020). Affective context and its uncertainty drive momentary affective experience. Emotion. https://doi.org/10.1037/emo0000912

Atwood, G., \& Stolorow, R. (1984). Structures of subjectivity: Explorations in psychoanalytic phenomenology. Analytic Press.

Auletta, A. F., \& Salvatore, S. (2009). The grid of the models of interpretations: Coding manual. Unpublished manuscript.

Auletta, A. F., Salvatore, S., Metrangolo, R., Monteforte, G., Pace, V., \& Puglisi, M. (2012). The Grid of the Models of Interpretations (GMI): A trans-theoretical method to study therapist interpretive activity. Journal of Psychotherapy Integration, 22(2), 61-84. https://doi.org/10.1037/a0028009

Baradon, T., Biseo, M., Broughton, C., James, J., \& Joyce, A. (2016). Principles \& practice of psychoanalytic parent-infant psychotherapy: Claiming the baby. Routledge.

Barkham, M., \& Shapiro, D. A. (1986). Counselor verbal response modes and experienced empathy. Journal of Counseling Psychology, 33(1), 3-10. https://doi.org/10.1037/00220167.33.1.3

Barrett, L. F. (2017). The theory of constructed emotion: An active inference account of interoception and categorization. Social Cognitive and Affective Neuroscience, 12(1), 1-23. https://doi.org/10.1093/scan/nsw154 
Barrett, L. (2020). Hypotheses about emotional development in the theory of constructed emotion: A response to developmental perspectives on how emotions are made. Human Development, 64(2), 52-54. https://doi.org/10.1159/000508988

Bateman, A. M., \& Fonagy, P. (2013). Psychoanalytic inquiry: A topical journal for mental health professionals' mentalization-based treatment. Psychoanalytic Inquiry, 33(6), 595-613. https://doi.org/10.1080/07351690.2013.835170

Bateman, A. M., \& Holmes, J. (1995). Introduction to psychoanalysis: Contemporary theory and practice. Routledge.

Benzécri, J. P. (1973). L'analyse des donnees. Dunod.

Benzécri, J. P. (1979). Sur le calcul des taux d'inertie dans l'analyse d'un questionnaire, addendum et erratum. Cahiers de l'Analyse des Données, 4(3), 377-378. http://www.numdam.org/item/ CAD_1979_4_3_377_0/

Bolasco, S. (1999). Analisi multidimensionale dei dati. Metodi, strategie e criteri d'interpretazione. [Multidimensional analysis of data. Methods, strategies and criteria for interpretation]. Carocci.

Bond, M., Banon, E., \& Grenier, M. (1998). Differential effects of interventions on the therapeutic alliance with patients with personality disorders. Journal of Psychotherapy Practice \& Research, 7, 301-318.

Brumberg, J., \& Gumz, A. (2012). Transference interpretations and how they work: A systematic review. Zeitschrift fur Psychosomatische Medizin und Psychotherapie, 58(3), 219-235. https://doi.org/10.13109/zptm.2012.58.3.219

Bucci, W. (2011). The interplay of subsymbolic and symbolic processes in psychoanalytic treatment: It takes two to tango- - but who knows the steps, who's the leader? The choreography of the psychoanalytic interchange. Psychoanalytic Dialogues, 21(1), 45-54. https://doi.org/10.1080/10481885.2011.545326 
Bucci, W. (2021). Development and validation of measures of referential activity. Journal of Psycholinguistic Research, 50(1), 17-27. https://doi.org/10.1007/s10936-021-09760-9

Bucci, W., \& Cornell, W. F. (2020). Emotional communication and therapeutic change: Understanding psychotherapy through multiple code theory. Routledge.

Bucci, W., \& Maskit, B. (2006). A weighted referential activity dictionary. In Computing attitude and affect in text: Theory and applications (pp. 49-60). Springer-Verlag. https://doi.org/10.1007/1-4020-4102-0_6

Bucci, W., \& Maskit, B. (2007). Beneath the surface of the therapeutic interaction: The psychoanalytic method in modern dress. Journal of the American Psychoanalytic Association, 55(4), 1355-1397. https://doi.org/10.1177/000306510705500412

Bucci, W., Maskit, B., \& Murphy, S. (2016). Connecting emotions and words: The referential process. Phenomenology and the Cognitive Sciences, 15(3), 359-383. https://doi.org/10.1007/s11097-015-9417-z

Bucci, W., \& McKay, R. K. (2014 [1992]). Manual for scoring RA scales. Figshare. https://doi.org/10.6084/m9.figshare.962956

Busch, F. (2000). What is a deep interpretation? Journal of the American Psychoanalytic Association, 48(1), 237-254. https://doi.org/10.1177/00030651000480010401

Caligor, E., Diamond, D., Yeomans, F. E., \& Kernberg, O. F. (2009). The interpretive process in the psychoanalytic psychotherapy of borderline personality pathology. Journal of the American Psychoanalytic Association, 57(2), 271-301. https://doi.org/10.1177/0003065109336183

Caspar, F., Pessier, J., Stuart, J., Safran, J., Samstag, L. W., \& Guirguis, M. (2000). One step further in assessing how interpretations influence the process of psychotherapy. Psychotherapy Research, 10(3), 309-320. https://doi.org/10.1093/PTR/10.3.309

Chambers, J. C., \& Bickhard, M. H. (2007). Culture, self and identity: Interactivist contributions to a metatheory for cultural psychology. Culture and Psychology, 13(3), 259-294. https://doi.org/10.1177/1354067X07079881 
Child, D. (2006). The essential of factor analysis (3rd ed.). Bloomsbury Academic.

Christian, C., Barzilai, E., Nyman, J., \& Negri, A. (2021). Assessing key linguistic dimensions of ruptures in the therapeutic alliance. Journal of Psycholinguistic Research, 50(1), 143-153. https://doi.org/10.1007/s10936-021-09768-1

Coen, S. J. (2003). The thrall of the negative and how to analyze it. Journal of the American Psychoanalytic Association, 51(2), 465-489. https://doi.org/10.1177/00030651030510020301

Coen, S. J. (2005). How to play with patients who would rather remain remote. Journal of the American Psychoanalytic Association, 53(3), 811-834.

https://doi.org/10.1177/00030651050530030601

Cohen, J. (1960). A coefficient of agreement for nominal scales. Educational and Psychological Measurement, 20(1), 37-46. https://doi.org/10.1177/001316446002000104

Connolly, M., Crits-Christoph, P., Shappell, S., Barber, J., Luborsky, L., \& Shaffer, C. (1999). Relation of transference interpretations to outcome in the early sessions of brief supportiveexpressive psychotherapy. Psychotherapy Research, 9(4), 485-495. https://doi.org/10.1080/10503309912331332881

Crits-Christoph, P., Gibbons, M. B. C., \& Mukherjee, D. (2013). Psychotherapy process-outcome research. In M. J. Lambert (Ed.), Bergin and Garfield's handbook of psychotherapy and behavior change (Vol. 6, pp. 298-340). John Wiley \& Sons.

Damasio, A. (2010). Self comes to mind: Constructing the conscious brain. Pantheon/Random House.

Diener, M. J., Hilsenroth, M. J., \& Weinberger, J. (2007). Therapist affect focus and patient outcomes in psychodynamic psychotherapy: A meta-analysis. The American Journal of Psychiatry, 164(6), 936-941. https://doi.org/10.1176/AJP.2007.164.6.936

Dimaggio, G., Ottavi, P., Popolo, R., \& Salvatore, G. (2020). Metacognitive interpersonal therapy: Body, imagery and change. Routledge.

Etchegoyen, R. H. (2005). The fundamentals of psychoanalytic technique. Routledge. 
Exner, J. E. (2003). The Rorschach: A comprehensive system. Vol. 1. Basic foundations and principles of interpretation. (4th ed.). Wiley.

Faustino, B., \& Vasco, A. B. (2020). Relationships between emotional processing difficulties and early maladaptive schemas on the regulation of psychological needs. Clinical Psychology and Psychotherapy, 27(6), 804-813. https://doi.org/10.1002/cpp.2464

Fleiss, J. L. (1971). Measuring nominal scale agreement among many raters. Psychological Bulletin, 76(5), 378-382. https://doi.org/10.1037/h0031619

Fleiss, J. L. (1981). Statistical methods for rates and proportions. John Wiley \& Sons.

Fleiss, J. L., \& Cohen, J. (1973). The equivalence of weighted kappa and the intraclass correlation coefficient as measures of reliability. Educational and Psychological Measurement, 33(3), 613-619. https://doi.org/10.1177/001316447303300309

Frank, J. D., \& Frank, J. B. (1991). Persuasion and healing: A comparative study of psychotherapy (3rd ed.). Johns Hopkins University Press.

Freud, S., Strachey, J., \& Richards, A. (1973). New introductory lectures on psychoanalysis. Harmondsworth: Penguin.

Gabbard, G. O. (2005). Psychodynamic psychiatry in clinical practice (4th ed.). American Psychiatric Publishing, Inc.

Gabbard, G. O. (2007). Gabbard's treatments of psychiatric disorders (4th ed.). American Psychiatric Publishing Inc.

Gabbard, G. O. (Ed.). (2009). Textbook of psychotherapeutic treatments. American Psychiatric Publishing, Inc.

Gabbard, G. O., \& Horowitz, M. J. (2009). Insight, transference interpretation, and therapeutic change in the dynamic psychotherapy of borderline personality disorder. Treatment in Psychiatry, 166(5), 517-521. 
Gazzola, N., \& Stalikas, A. (2004). Therapist interpretations and client processes in three therapeutic modalities: Implications for psychotherapy integration. Journal of Psychotherapy Integration, 14(4), 397-418. https://doi.org/10.1037/1053-0479.14.4.397

Gelso, C. J., Kivlighan, D. M., Busa-Knepp, J., Spiegel, E. B., Ain, S., Hummel, A. M., Emilie, Y. M., \& Markin, R. D. (2012). The unfolding of the real relationship and the outcome of brief psychotherapy. Journal of Counseling Psychology, 59(4), 495-506. https://doi.org/10.1037/a0029838

Gennaro, A. (2011). The building of models as pathway to understand the therapeutic process. Integrative Psychological and Behavioral Science, 45, 355-365. https://doi.org/10.1007/s12124-011-9181-8

Gennaro, A., Goncalves, M., Mendes, I., Ribeiro, A., \& Salvatore, S. (2011). Dynamics of sensemaking and development of the narrative in the clinical exchange. Research in Psychotherapy: Psychopathology, Process and Outcome, 14(1), 90-120. https://doi.org/10.4081/ripppo.2011.44

Gennaro, A., Kipp, S., Viol, K., de Felice, G., Andreassi, S., Aichhorn, W., Salvatore, S., \& Schiepek, G. (2020). A phase transition of the unconscious: Automated text analysis of dreams in psychoanalytic psychotherapy. Frontiers in Psychology, 11, 1667. https://doi.org/10.3389/fpsyg.2020.01667

Gennaro, A., Salvatore, S., \& Rocco., D. (2016). Deconstructive and constructive processes in the therapeutic action: A focus on the relational modalities and patient thinking processes. Journal of Constructivist Psychology, 30(2), 105-126. https://doi.org/10.1080/10720537.2016.1183536

Gennaro, A., Salvatore, S., Rocco, D., \& Auletta, A. (2017). Deconstructive and constructive dynamics in the clinical process: A step further in the validation of the two-stage semiotic model. Journal of Constructivist Psychology, 30(2), 105-126. https://doi.org/10.1080/10720537.2016.1183536 
Gibbons, M. B. C., Crits-Christoph, P., Levinson, J., Gladis, M., Siqueland, L., Barber, J. P., \& Elkin, I. (2002). Therapist interventions in the interpersonal and cognitive therapy sessions of the treatment of Depression Collaborative Research Program. American Journal of Psychotherapy, 56(1), 3-26. https://doi.org/10.1176/appi.psychotherapy.2002.56.1.3

Gigerenzer, G., \& Goldstein, D. G. (1996). Reasoning the fast and frugal way: Models of bounded rationality. Psychological Review, 103(4), 650-669. doi:10.1037/0033-295X.103.4.650

Gilbert, P., \& Leahy, R. L. (2007). Introduction and overview: Basic issues in the therapeutic relationship. In The Therapeutic relationship in the cognitive behavioral psychotherapies (pp. 3-23). Taylor and Francis. https://doi.org/10.4324/9780203099995-8

Gonçalves, M. M., Matos, M., \& Santos, A. (2009). Narrative therapy and the nature of 'innovative moments' in the construction of change. Journal of Constructivist Psychology, 22(1), 1-23. https://doi.org/10.1080/10720530802500748

Gonçalves, Ó. F., \& Machado, P. P. P. (1999). Cognitive narrative psychotherapy: Research foundations. Journal of Clinical Psychology, 55(10), 1179-1191.

Greenberg, L. S. (2004). Emotion focused therapy. In Clinical Psychology and Psychotherapy, $11(1), 3-16$

Greenberg, L. S. (2007). A guide to conducting a task analysis of psychotherapeutic change. Psychotherapy Research, 17(1), 15-30. https://doi.org/10.1080/10503300600720390

Greenberg, L. S. (2021). Changing emotion with emotion: A practitioner's guide. https://doi.org/10.1037/0000248-000

Greenberg, L. S., \& Safran, J. D. (1989). Emotion in psychotherapy. American Psychologist, 44(1), 19-29. https://doi.org/10.1037/0003-066X.44.1.19

Gross, J. J. (2015). Emotion regulation: Current status and future prospects. Psychological Inquiry, 26(1), 1-26. https://doi.org/10.1080/1047840X.2014.940781

Haken, H., \& Schiepek, G. (2010). Synergetik in der Psychologie [Synergetics in psychology] (2nd ed.). Hogrefe. 
Hayes, A. M., Laurenceau, J. P., Feldman, G., Strauss, J. L., \& Cardaciotto, L. A. (2007). Change is not always linear: The study of nonlinear and discontinuous patterns of change in psychotherapy. Clinical Psychology Review, 27(6), 715-723. https://doi.org/10.1016/j.cpr.2007.01.008

Hersoug, A. G., Ulberg, R., \& Høglend, P. (2014). When is transference work useful in psychodynamic psychotherapy? Main results of the first experimental study of transference work (FEST). Contemporary Psychoanalysis, 50(1-2), 156-174. https://doi.org/10.1080/00107530.2014.880314

Higa, J. K., \& Gedo, P. M. (2012). Transference interpretation in the treatment of borderline personality disorder patients. Bulletin of the Menninger Clinic, 76(3), 195-210. https://doi.org/10.1521/BUMC.2012.76.3.195

Hill, C. E., \& Lambert, M. J. (2004). Methodological Issues in Studying Psychotherapy Processes and Outcomes. In M. J. Lambert (Ed.), Bergin and Garfield's Handbook of Psychotherapy and Behavior Change (pp. 87-135). New York: John Wiley \& Sons.

Hill, C. E., Lu, Y., Gerstenblith, J. A., Kline, K. V., Wang, R. J., \& Zhu, X. (2020). Facilitating client collaboration and insight through interpretations and probes for insight in psychodynamic psychotherapy: A case study of one client with three successive therapists. Psychotherapy, 57(2), 263-272. https://doi.org/10.1037/pst0000242

Høglend, P. (2004). Analysis of transference in psychodynamic psychotherapy: A review of empirical research. Canadian Journal of Psychoanalysis, 12(2), 279-300.

Høglend, P., Bøgwald, K. P., Amlo, S., Marble, A., Ulberg, R., Sjaastad, M. C., Sørbye, O., Heyerdahl, O., \& Johansson, P. (2008). Transference interpretations in dynamic psychotherapy: Do they really yield sustained effects? The American Journal of Psychiatry, 165(6), 763-771. https://doi.org/10.1176/APPI.AJP.2008.07061028

Joseph, B. (1992). Psychic change: Some perspectives. International Journal of PsychoAnalysis, 73, 237-243. 
Kernberg, O. F., Yeomans, F. E., Clarkin, J. F., \& Levy, K. N. (2008). Transference focused psychotherapy: Overview and update. International Journal of Psychoanalysis, 89(3), 601620. https://doi.org/10.1111/j.1745-8315.2008.00046.x

Lachmann, F. M., \& Beebe, B. (1993). Interpretation in a developmental perspective. Progress in Self Psychology, 9, 45-52.

Landis, J. R., \& Koch, G. G. (1977). An application of hierarchical kappa-type statistics in the assessment of majority agreement among multiple observers. Biometrics, 33(2), 363. https://doi.org/10.2307/2529786

Leahy, R. L. (2019). Introduction: Emotional schemas and emotional schema therapy. Journal Cognitive Therapy, 12, 1-4. https://doi.org/10.1007/s41811-018-0038-5

Lecours, S., Bouchard, M.-A., St-Amand, P., \& Perry, J. C. (2010). Assessing verbal elaboration of affect in psychotherapy: A preliminary report and single case study. Psychotherapy Research, 10(1), 47-56. https://doi.org/10.1080/713663593

Levy, K. N., Clarkin, J. F., Yeomans, F. E., Scott, L. N., Wasserman, R. H., \& Kernberg, O. F. (2006). The mechanisms of change in the treatment of borderline personality disorder with transference focused psychotherapy. Journal of Clinical Psychology, 62(4), 481-501. https://doi.org/10.1002/jclp.20239

Levy, K. N., \& Scala, J. W. (2012). Transference, transference interpretations, and transferencefocused psychotherapies. Psychotherapy, 49(3), 391-403. https://doi.org/10.1037/a0029371

Lo Verde, R.; Sarracino, D.; Vigorelli, M. (2012). Therapeutic Cycles and Referential Activity in the Analysis of the Therapeutic Process. Research in Pschotherapy, 15, 22-31

Lu, C. W., \& Reynolds, M. R. (2001). CUSUM charts for monitoring an autocorrelated process. Journal of Quality Technology, 33(3), 316-334. https://doi.org/10.1080/00224065.2001.11980082

Luborsky, L., \& Crits-Christoph, P. (1990). Understanding transference: The core conflictual relationship theme method. Basic Books. 
Luborsky, L., Popp, C., Luborsky, E., \& Mark, D. (1994). The core conflictual relationship theme. Psychotherapy Research, 4(3-4), 172-183. https://doi.org/10.1080/10503309412331334012 https://doi.org/10.1348/147608310X520436

Mariani, R., \& Hoffman, L. (2021). Analytic process and linguistic style: Exploring analysts' treatment notes in the light of linguistic measures of the referential process. Journal of Psycholinguist Research, 50, 193-206. https://doi.org/10.1007/s10936-021-09771-6

Mariani, R., Maskit, B., Bucci, W., \& De Coro, A. (2013). Linguistic measures of the referential process in psychodynamic treatment: The English and Italian versions. Psychotherapy Research, 23(4), 430-447. https://doi.org/10.1080/10503307.2013.794399

Mariani, R., \& Negri, A. (2015). Note del terapeuta e misure del processo referenziale. Un possibile terzo analitico. Ricerca Psicoanalitica, 3, 119-133. doi:10.3280/RPR2015-003009

Maskit, B. (2012). Provisional norms of psychotherapy sessions for measures of the referential process. https://sites.google.com/site/referentialprocess/dictionary-measures-and-computerprograms/norms-for-psychotherapy-sessions-for-select-measures

Maskit, B. (2014a). The Discourse Attributes Analysis Program (DAAP) operating instructions. https://doi.org/10.6084/M9.FIGSHARE.947740.V3

Maskit, B. (2014b). DAAPMath. https://doi.org/10.6084/m9.figshare.928469.v1

Maskit, B. (2014c). DAAP using time as independent variable: Technical aspects. https://doi.org/10.6084/m9.figshare.947741.v1

Maskit, B. (2021). Overview of computer measures of the referential process. Journal of Psycholinguistic Research. https://doi.org/10.1007/s10936-021-09761-8

Maskit, B., \& Murphy, S. (2011). The Discourse Attributes Analysis Program. http://www.thereferentialprocess.org/the-discourse-attributes-analysis-program-daap

McCulloh, I., \& Carley, K. M. (2011). Detecting change in longitudinal social network. Journal of Social Structure, 12(1), 1-37. https://doi.org/10.21307/joss-2019-031 
McCullough, L., Winston, A., Farber, B. A., Porter, F., Pollack, J., Laikin, M., Vingiano, W., \& Trujillo, M. (1991). The relationship of patient-therapist interaction to outcome in brief psychotherapy. Psychotherapy, 28(4), 525-533. https://doi.org/10.1037/0033-3204.28.4.525

McWilliams, N. (1994). Psychoanalytic diagnosis: Understanding personality structure in the clinical process. Guilford Press.

McWilliams, N. (1998). Psychoanalytic psychotherapy. Guilford Press.

Mergenthaler, E. (1996). Emotion-abstraction patterns in verbatim protocols: A new way of describing therapeutic processes. Journal of Consulting and Clinical Psychology, 64, 13061318. doi:10.1037//0022-006X.64.6.1306

Millsap, R. E., Van der Ark, L. A., Bolt, D. M., \& Woods, C. M. (2016). New developments in quantitative psychology (Vol. 66). Springer-Verlag New York.

Modell, A. H. (1984). Psychoanalysis in a new context. International Universities Press.

Modell, A. H. (1986). A narcissistic defense against affects and the illusion of self-sufficiency. In A. P. Morrison (Ed.), Essential papers on narcissism (pp. 293-307). New York University Press.

Moltrecht, B., Deighton, J., Patalay, P., \& Edbrooke-Childs, J. (2020). Effectiveness of current psychological interventions to improve emotion regulation in youth: A meta-analysis. European child and adolescent psychiatry. https://doi.org/10.1007/s00787-020-01498-4

Morris, L., \& Mansell, W. (2018). A systematic review of the relationship between rigidity/flexibility and transdiagnostic cognitive and behavioral processes that maintain psychopathology. Journal of Experimental Psychopathology, 9(3), 1-40. https://doi.org/10.1177/2043808718779431

Muramatsu, R., \& Hanoch, Y. (2005). Emotions as a mechanism for boundedly rational agents: The fast and frugal way. Journal of Economic Psychology, 26(2), 201-221.

Negri, A., Andreoli, G., Barazzetti, A., Zamin, C., \& Christian, C. (2020). Linguistic markers of the emotion elaboration surrounding the confinement period in the Italian epicenter of the 
COVID-19 outbreak. Frontiers in Psychology, 11, 568281.

https://doi.org/10.3389/fpsyg.2020.568281

Negri, A., Andreoli, G., Mariani, R., De Bei, F., Rocco, D., Greco, A., \& Bucci, W. (2020).

First validation of the referential process post-session scale-therapist version (RPPS-

T). Clinical Neuropsychiatry, 17 (6), 319-329.

https://doi.org/10.36131/cnfioritieditore20200601

Negri, A., Christian, C., Mariani, R., Belotti, L., Andreoli, G., \& Danskin, K. (2019). Linguistic features of the therapeutic alliance in the first session: A psychotherapy process study. Research in Psychotherapy: Psychopathology, Process and Outcome, 22(1), 71-82. https://doi.org/10.4081/ripppo.2019.374

Negri, A., Esposito, G., Mariani, R., Savarese, M., Belotti, L., Squitieri, B., \& Bucci, W. (2018). The Italian weighted reflection and reorganization list (I-WRRL): A new linguistic measure detecting the third phase of the referential process. Proceedings XII National Congress of the Society for Psychotherapy Research, Italian Section. Palermo, Italy, 5-6 October 2018. Research in Psychotherapy: Psychopathology, Process and Outcome, 21(1), 5-6.

Negri, A., \& Ongis, M. (2021). Stimulus features of the object relations technique affecting the linguistic qualities of individuals' narratives. Journal of Psycholinguistic Research, 50(1), 65-83. https://doi.org/10.1007/s10936-021-09764-5

Nitti, M., Ciavolino, E., Salvatore, S., \& Gennaro, A. (2010). Analyzing psychotherapy process as intersubjective sensemaking: An approach based on discourse analysis and neural networks. Psychotherapy Research, 20(5), 546-563. https://doi.org/10.1080/10503301003641886

Ogden, P., \& Fisher, J. (2015). Sensorimotor psychotherapy: Interventions for trauma and attachment. WW Norton \& Company.

Ogrodniczuk, J. S., \& Piper, W. E. (1999). Measuring therapist technique in psychodynamic psychotherapies: Development and use of a new scale. Journal of Psychotherapy Practice and Research, 8(2), 142-154. 
Page, E. S. (1954). Continuous inspection schemes. Biometrika, 41(1/2), 100. https://doi.org/10.2307/2333009

Pascual-Leone, A., \& Greenberg, L. S. (2007). Emotional processing in experiential therapy: Why 'the only way out is through'. Journal of Consulting and Clinical Psychology, 75(6), 875887. https://doi.org/10.1037/0022-006X.75.6.875

Phillipson, H. (1955). The object relations technique. Free Press.

Pignatiello, J. J., \& Runger, G. C. (1990). Comparisons of multivariate CUSUM charts. Journal of Quality Technology, 22(3), 173-186. https://doi.org/10.1080/00224065.1990.11979237

Pitillas, C. (2020). Common therapeutic elements of interventions aimed at enhancing parent-child early relationships. Psychoanalytic Psychology, 37(1), 28-36.

https://doi.org/10.1037/PAP0000234

Piper, W. E., Azim, H. F. A., Joyce, A. S., \& McCallum, M. (1991). Transference interpretations, therapeutic alliance, and outcome in short-term individual psychotherapy. Archives of General Psychiatry, 48, 946-953. doi:10.1001/archpsyc.1991.01810340078010

Piper, W. E., Joyce, A. S., McCallum, M., \& Azim, H. F. (1993). Concentration and correspondence of transference interpretations in short-term psychotherapy. Journal of Consulting and Clinical Psychology, 61, 586-595. doi:10.1037/0022-006X.61.4.586

Piper, W. E., Joyce, A. S., McCallum, M., \& Azim, H. F. A. (1998). Interpretive and supportive forms of psychotherapy and patient personality variables. Journal of Consulting and Clinical Psychology, 66, 558-567. doi:10.1037/0022-006X.66.3.558

Piper, W. E., Ogrodniczuk, J. S., Joyce, A. S., McCallum, M., Rosie, J. S., O’Kelley, J. G., \& Steinberg, P. I. (1999). Prediction of dropping out in time-limited, interpretive individual psychotherapy. Psychotherapy: Theory, Research, Practice, Training, 36, 114-122. doi:10.1037/h0087787

Renzi, A., Mariani, R., Di Trani, M., \& Tambelli, R. (2020). Giving words to emotions: The use of linguistic analysis to explore the role of alexithymia in an expressive writing intervention. 
Research in Psychotherapy Process and Outcome, 23, 2.

https://doi.org/10.4081/ripppo.2020.452

Ridenour, J. M. (2016). Psychodynamic model and treatment of schizotypal personality disorder.

Psychoanalytic Psychology, 33(1), 129-146. https://doi.org/10.1037/a0035531

Rocco, D., Gennaro, A., Salvatore, S., Stoycheva, V., \& Bucci, W. (2017). Clinical mutual attunement and the development of therapeutic process: A preliminary study. Journal of Constructivist Psychology, 30(4), 371-387. https://doi.org/10.1080/10720537.2016.1227950

Rocco, D., Pastore, M., Gennaro, A., Salvatore, S., Cozzolino, M., \& Scorza, M. (2018). Beyond verbal behavior: An empirical analysis of speech rates in psychotherapy sessions. Frontiers in Psychology, 9(Jun), 978. https://doi.org/10.3389/fpsyg.2018.00978

Rycroft, C. (1968). Imagination and reality. Hogarth.

Salvatore, S., \& Freda, M. F. (2011). Affect, unconscious and sensemaking. A psychodynamic, semiotic and dialogic model. New Ideas in Psychology, 29(2), 119-135. https://doi.org/10.1016/j.newideapsych.2010.06.001

Salvatore, S., Gelo, O., Gennaro, A., Manzo, S., \& Al Radaideh, A. (2010). Looking at the psychotherapy process as an intersubjective dynamic of meaning-making: A case study with discourse flow analysis. Journal of Constructivist Psychology, 23(3), 195-230. https://doi.org/10.1080/10720531003765981

Salvatore, S., \& Tschacher, W. (2012). Time dependency of psychotherapeutic exchanges: The contribution of the theory of dynamic systems in analyzing process. Frontiers in Psychology, 3, 253. https://doi.org/10.3389/fpsyg.2012.00253

Schiepek, G., Aichhorn, W., Gruber, M., Strunk, G., Bachler, E., \& Aas, B. (2016). Real-time monitoring of psychotherapeutic processes: Concept and compliance. Frontiers in Psychology, 7(May), 604. https://doi.org/10.3389/fpsyg.2016.00604

Schiepek, G., Aichhorn, W., \& Schöller, H. (2018). Monitoring change dynamics: A nonlinear approach to psychotherapy feedback. Chaos \& Complexity Letters, 11(3), 355-375. 
Schöller, H., Viol, K., Aichhorn, W., Hütt, M. T., \& Schiepek, G. (2018). Personality development in psychotherapy: A synergetic model of state-trait dynamics. Cognitive Neurodynamics, 12(5), 441-459. https://doi.org/10.1007/s11571-018-9488-y

Schut, A. J., Castonguay, L. G., Flanagan, K. M., Yamasaki, A. S., Barber, J. P., Bedics, J. D., \& Smith, T. L. (2005). Therapist interpretation, patient-therapist interpersonal process, and outcome in psychodynamic psychotherapy for avoidant personality disorder. Psychotherapy, 42(4), 494-511. https://doi.org/10.1037/0033-3204.42.4.494

Shrout, P. E., \& Fleiss, J. L. (1979). Intraclass correlations: Uses in assessing rater reliability. Psychological Bulletin, 86(2), 420-428. https://doi.org/10.1037//0033-2909.86.2.420

Silberschatz, G., Fretter, P. B., \& Curtis, J. T. (1986). How do interpretations influence the process of psychotherapy? Journal of Consulting and Clinical Psychology, 54(5), 646-652. https://doi.org/10.1037//0022-006x.54.5.646

Silva, D. R., \& Ferreira, A. S. (2014). The effect of color on the production of responses to Rorschach cards VIII, IX, and X in age groups of 11-12 and 15-16 years. Journal of Personality Assessment, 96, 426-431. https://doi.org/10.1080/00223891.2013.876426

Spiegal, S. B., \& Hill, C. E. (1989). Guidelines for research on therapist interpretation: Toward greater methodological rigor and relevance to practice. Journal of Counseling Psychology, 36(1), 121-129. https://doi.org/10.1037/0022-0167.36.1.121

Steiner, J. (1996). The aim of psychoanalysis in theory and in practice. International Journal of Psychoanalysis, 77, 1073-1083.

Stern, D. B. (1997). Unformulated experience: From dissociation to imagination in psychoanalysis. The Analytic Press.

Stern, D. B. (2004). The eye sees itself: Dissociation, enactment, and the achievement of conflict. Contemporary Psychoanalysis, 40(2), 197-237. https://doi.org/10.1080/00107530.2004.10745828 
Stolorow, R. D. (1997). Dynamic, dyadic, intersubjective systems: An evolving paradigm for psychoanalysis. Psychoanalytic Psychology, 14(3), 337-346. https://doi.org/10.1037/h0079729

Stolorow, R. D. (2002). From drive to affectivity: Contextualizing psychological life. Psychoanalytic Inquiry, 22(5), 678-685. https://doi.org/10.1080/07351692209349012

Stolorow, R. D., \& Atwood, G. E. (1984). Psychoanalytic phenomenology: Toward a science of human experience. Psychoanalytic Inquiry, 4(1), 87-105. DOI:10.1080/07351698409533532

Stolorow, R. D., \& Atwood, G. E. (1992). Contexts of being: The intersubjective foundations of psychological life (Vol. 12). Analytic Press, Inc.

Stolorow, R. D., Atwood, G. E., \& Brandchaft, B. (Eds.) (1994). The intersubjective perspective. Jason Aronson.

Stolorow, R. D., Brandchaft, B., \& Atwood, G. E. (1987). Psychoanalytic treatment: An intersubjective approach. The Analytic Press.

Strachey, J. (1937). Symposium on the theory of the therapeutic results of psycho-analysis. The International Journal of Psycho-Analysis, 18, 139.

Summers, F. (2001). What I do with what you give me: Therapeutic action as the creation of meaning. Psychoanalytic Psychology, 18(4), 635-655. https://doi.org/10.1037/07369735.18.4.635

Summers, F. (2005). Therapeutic action, epistemology, and the ethic of psychoanalysis. International Journal of Applied Psychoanalytic Studies, 2(3), 220-235. https://doi.org/10.1002/aps.11

Summers, R. F., \& Barber, J. P. (2010). Psychodynamic therapy: A guide to evidence-based practice. Guilford Press.

Tschacher, W., \& Ramseyer, F. (2009). Modeling psychotherapy process by time-series panel analysis (TSPA). Psychotherapy Research, 19(4-5), 469-481.

https://doi.org/10.1080/10503300802654496 
Venuleo, C., Salvatore, G., Ruggieri, R. A., Marinaci, T., Cozzolino, M., \& Salvatore, S. (2020). Steps towards a unified theory of psychopathology: The phase space of meaning model. Clinical Neuropsychiatry, 17(4), 236-252. https://doi.org/10.36131/cnfioritieditore20200405

Voutilainen, L., Peräkylä, A., \& Ruusuvuori, J. (2010). Recognition and interpretation: Responding to emotional experience in psychotherapy. Research on Language and Social Interaction, 43(1), 85-107. https://doi.org/10.1080/08351810903474799

Westen, D., \& Shedler, J. (1999a). Revising and assessing axis II, part I: Developing a clinically and empirically valid assessment method. American Journal of Psychiatry, 156(2), 258-272. https://doi.org/10.1176/ajp.156.2.258

Westen, D., \& Shedler, J. (1999b). Revising and assessing axis II, part II: Toward an empirically based and clinically useful classification of personality disorders. American Journal of Psychiatry, 156(2), 273-285. https://doi.org/10.1176/ajp.156.2.273

Wheeler, Z. (2013). Treatment of schizoid personality: An analytic psychotherapy handbook. https://digitalcommons.pepperdine.edu/etd/413

Winston, A., McCollugh, L., Laikin, M. (2018). Clinical and Research Implications of PatientTherapist Interaction in Brief Psychotherapy. In American Journal of Psychotherapy, 47(4), 473-644 https://doi.org/10.1176/appi.psychotherapy.1993.47.4.527

Wiser, S., \& Goldfried, M. R. (1996). Verbal interventions in significant psychodynamicinterpersonal and cognitive-behavioral therapy sessions. Psychotherapy Research, 6(4), 309319. https://doi.org/10.1080/10503309612331331828

Wolf, E. S. (1993). The role of interpretation in therapeutic change. In A. Goldberg (Ed.), The widening scope of self psychology (pp. 15-30). Analytic Press, Inc.

Woodall, W. H. (2006). The use of control charts in health-care and public-health surveillance. Journal of Quality Technology, 38(2), 89-104. https://doi.org/10.1080/00224065.2006.11918593 
Zhou, Y., Maskit, B., Bucci, W., Fishman, A., \& Murphy, S. (2021). Development of WRRL: A new computerized measure of the reflecting/reorganizing function. Journal of Psycholinguistic Research, 50(1), 51-64. https://doi.org/10.1007/s10936-021-09762-7 


\section{Tables and Figures}

Table 1. Comparison between pre- and post-treatment CCRT formulations of Max's case

\begin{tabular}{|c|c|c|}
\hline CCRT component & Pre-treatment & Post-treatment \\
\hline Wishes & $\begin{array}{l}\text { "I wish to be loved and } \\
\text { understood" ( } 75 \%) \text {; "close and } \\
\text { accepting" }(50 \%)\end{array}$ & $\begin{array}{l}\text { "I wish to be loved and } \\
\text { understood" ( } 40 \%) \text { " "to assert } \\
\text { self and be independent" (30\%) }\end{array}$ \\
\hline Response from Other & $\begin{array}{l}\text { "Rejecting and opposing" } \\
(92 \%) \text {; "upset" }(42 \%)\end{array}$ & $\begin{array}{l}\text { "Likes me" (40\%); "rejecting } \\
\text { and opposing" }(30 \%)\end{array}$ \\
\hline Response from Self & $\begin{array}{l}\text { "I feel disappointed and } \\
\text { depressed" (78\%); "anxious and } \\
\text { ashamed" }(50 \%)\end{array}$ & $\begin{array}{l}\text { "Feels helpful" }(80 \%) ; \\
\text { "respected and accepted" }(30 \%)\end{array}$ \\
\hline
\end{tabular}


Table 2. Comparison between the pre- and post-treatment SWAP-200 assessment for Max's personality dimensions with scores exceeding cut-off values.

\begin{tabular}{lcc}
\hline Personality Dimensions & Pre-treatment & Post-treatment \\
\hline Schizoid & 61.18 & 47.04 \\
Schizotypal & 51.06 & 41.27 \\
Avoidant & 56.92 & 41.42 \\
Obsessive-compulsive & 58.65 & 54.87 \\
High functioning & 61.15 & 70.21 \\
\hline
\end{tabular}


Table 3. Variables and dimensions characterizing the grid of the models of interpretation

\begin{tabular}{|c|c|c|c|}
\hline Dimension & Category & Description & Example \\
\hline \multirow[t]{5}{*}{ Content } & Representation & $\begin{array}{l}\text { Interpretation focuses on the } \\
\text { patient's ideas, mental schemas, or } \\
\text { fantasies. }\end{array}$ & $\begin{array}{l}\text { "You conveyed to me that you } \\
\text { regularly feel as being put } \\
\text { aside, in your relations with } \\
\text { your mother, your partner, } \\
\text { maybe...". }\end{array}$ \\
\hline & Defense & $\begin{array}{l}\text { Interpretation focuses on the } \\
\text { patient's tendency to protect } \\
\text { him/herself from painful, } \\
\text { unacceptable external situations or } \\
\text { inner experiences. }\end{array}$ & $\begin{array}{l}\text { "That's interesting, because if } \\
\text { you ignore her, or you don't } \\
\text { think of it as a rejection, well, } \\
\text { you can ignore your feeling of } \\
\text { being deserted." }\end{array}$ \\
\hline & Motive & $\begin{array}{l}\text { Interpretation focuses on the } \\
\text { patient's mental schemas, } \\
\text { behaviors, or attitudes that have a } \\
\text { purpose, such as getting something } \\
\text { from someone or changing an } \\
\text { inner state or interpersonal } \\
\text { situation. }\end{array}$ & $\begin{array}{l}\text { "Maybe you were intended to } \\
\text { go to Milan just to stay alone } \\
\text { with dad..." }\end{array}$ \\
\hline & $\begin{array}{l}\text { General } \\
\text { functioning }\end{array}$ & $\begin{array}{l}\text { Interpretation focuses on the } \\
\text { patient's general ways of acting or } \\
\text { behaving with respect to self or } \\
\text { others. }\end{array}$ & $\begin{array}{l}\text { "At the beginning of the } \\
\text { therapy, I had the feeling that } \\
\text { here, by coming to therapy, } \\
\text { you're attempting to imitate the } \\
\text { relationship with your father... } \\
\text { you're playing the role of the } \\
\text { child." }\end{array}$ \\
\hline & Drive & $\begin{array}{l}\text { Interpretation focuses on drives, } \\
\text { wishes, and instincts. }\end{array}$ & $\begin{array}{l}\text { "I think you always felt } \\
\text { compelled to stay alone with } \\
\text { dad...." }\end{array}$ \\
\hline \multirow{3}{*}{ Domain } & Affect & $\begin{array}{l}\text { Interpretation focuses on the } \\
\text { patient's emotional or affective } \\
\text { state, such as fear, love, or rage. }\end{array}$ & $\begin{array}{l}\text { "Now you are facing all of this } \\
\text { by yourself...the examinations, } \\
\text { the divorce...I think you're } \\
\text { getting frightened about that." }\end{array}$ \\
\hline & Intrapsychic & $\begin{array}{l}\text { Interpretation focuses on content } \\
\text { pertaining to the patient's self. }\end{array}$ & $\begin{array}{l}\text { "You're feeling overwhelmed } \\
\text { and you must run away. It's } \\
\text { like you're fearing your own } \\
\text { reactions." }\end{array}$ \\
\hline & Interpersonal & $\begin{array}{l}\text { Interpretation focuses on content } \\
\text { pertaining to others. }\end{array}$ & $\begin{array}{l}\text { "And this is expressing all your } \\
\text { helplessness...Maybe with your } \\
\text { father, too, you had this kind of } \\
\text { competition." }\end{array}$ \\
\hline Timeframe & Present & $\begin{array}{l}\text { Interpretation focuses on the } \\
\text { present moments of the patient's } \\
\text { life. }\end{array}$ & $\begin{array}{l}\text { "I think you're afraid of your } \\
\text { rage, somehow, so you're afraid } \\
\text { it goes out, this is such an inner } \\
\text { fight...." }\end{array}$ \\
\hline
\end{tabular}


Interpretation links events

Present-to-past belonging to the present with past issues.

Past

Interpretation focuses on the past moments of the patient's life.

Interpretation links events

Past-to-present belonging to the past with present issues.

Space

frame

Internal

External

Interpretation focuses on what

happens outside the sessions.

Interpretation is provided by the

Style Factual therapist as something that he/she considers sure and certain - a fact.

Interpretation is delivered with a degree of uncertainty. The

Subjective therapist may communicate his/her own point of view, state caution, or present interpretation to the patient as something needing to be tested.

Interpretation is delivered by

Demonstrating explaining how he/she attained it, offering examples, and/or reporting anecdotes.
"What you're feeling now, with me, it is far similar to what you experienced as a child, when you left home for the first time."

"And I guess, at times, this episode made you look for some loneliness."

"It was last session, you told me you were sorry for me, for what happened...I think even now you're afraid you're not good, for what you are, for how you look..."

"Even with me, sometimes you're feeling you can't, you've no hope, but sometimes you feel very strong... it's the same with your work plans."

"Maybe he reminded you so much of your father, his character, his constant control, almost anxious."

"So this is attractive for you, since it reminds you of your need to turn everything upside down."

"I don't know if I understand: I think you're on the lookout, in every new relationship. Isn't it?"

"And if we try to remember, this happens every time you must start to do something. The first time you came here, you said that you were reluctant to enter into therapy... and yesterday you presented your curriculum and are waiting for a call...." 
Table 4. Description of factors retrieved by the grid of the models of interpretation (GMI)

\section{Factor description}

\begin{tabular}{|c|c|c|c|c|c|c|c|c|}
\hline Number & Interpretation & Pole & Pole description & Content & Domain & $\begin{array}{l}\text { Time } \\
\text { orientation }\end{array}$ & $\begin{array}{l}\text { Space } \\
\text { frame }\end{array}$ & Style \\
\hline \multirow{2}{*}{1} & \multirow{2}{*}{ General models } & Negative & $\begin{array}{l}\text { Focus on patient's schemes pertaining to past } \\
\text { relations }\end{array}$ & Representation & Interpersonal & Past & External & \\
\hline & & Positive & Focus on patient's current intrapsychic states & Affect & Intrapsychic & Present & Internal & \\
\hline \multirow[t]{2}{*}{2} & \multirow[t]{2}{*}{ Affective states } & Negative & $\begin{array}{l}\text { Focus on what happens during the therapy } \\
\text { sessions }\end{array}$ & & & $\begin{array}{l}\text { Past-to- } \\
\text { present, } \\
\text { present-to- } \\
\text { past }\end{array}$ & Internal & Demonstrating \\
\hline & & Positive & $\begin{array}{l}\text { Focus on patient's affect states felt outside the } \\
\text { session }\end{array}$ & Affect & & Past & External & Factual \\
\hline \multirow{2}{*}{3} & \multirow{2}{*}{ Situated } & Negative & $\begin{array}{l}\text { Focus on patient's modalities of acting or } \\
\text { behaving }\end{array}$ & Functioning & Interpersonal & Present & & Factual \\
\hline & & Positive & Focus on patient's affect states & Affect & & $\begin{array}{l}\text { Past, present- } \\
\text { to-past }\end{array}$ & & Demonstrating \\
\hline \multirow[b]{2}{*}{4} & \multirow[b]{2}{*}{ Subjective } & Negative & Focus on patient's wishes or defenses & Drive, defense & & $\begin{array}{l}\text { Present-to- } \\
\text { past, past-to- } \\
\text { present }\end{array}$ & & \\
\hline & & Positive & $\begin{array}{l}\text { Focus on patient's actions or behaviors with } \\
\text { respect to self or others }\end{array}$ & Functioning & & $\begin{array}{l}\text { Past-to- } \\
\text { present, } \\
\text { present-to- } \\
\text { past }\end{array}$ & & Subjective \\
\hline \multirow{2}{*}{5} & \multirow{2}{*}{ Transference } & Negative & $\begin{array}{l}\text { Focus on patient's defenses and goals, linking } \\
\text { events belonging to different timeframes }\end{array}$ & $\begin{array}{l}\text { Defense, } \\
\text { motive }\end{array}$ & & $\begin{array}{l}\text { Past-to- } \\
\text { present, past }\end{array}$ & & \\
\hline & & Positive & $\begin{array}{l}\text { Focus on patient's schemes pertaining to the } \\
\text { relationship with the therapist }\end{array}$ & Representation & Interpersonal & Present & Internal & \\
\hline
\end{tabular}

\section{GMI categorie}

\section{GMI categories}


Table 5. Identified trends of sessions according to detected trends

\begin{tabular}{llll}
\hline \multicolumn{2}{l}{ IWRAD_IWRRL } & \multicolumn{2}{l}{ IWRAD_IREF } \\
\hline Trend & Session & Trend & Sessions \\
\hline Increasing & $1-19$ & Decreasing & $1-28$ \\
Decreasing & $20-33$ & Increasing & $29-46$ \\
Increasing & $34-54$ & Decreasing & $47-69$ \\
Decreasing & $55-76$ & Increasing & $70-76$ \\
\hline
\end{tabular}


Table 6. Logistic regression model with interpretative factors as predictors of the IWRAD_IWRRL trend

\begin{tabular}{lcccccc}
\hline Factor & $\boldsymbol{B}$ & $\boldsymbol{S E}$ & Wald & $\boldsymbol{d} \boldsymbol{f}$ & $\boldsymbol{p}$ & $\boldsymbol{O R}$ \\
\hline F1 - General models & 0.143 & 4.254 & 0.001 & 1 & 0.973 & 1.154 \\
F2 - Affective states & 28.505 & 11.368 & 6.287 & 1 & 0.012 & 2.396 \\
F3 - Situated & 18.006 & 8.942 & 4.055 & 1 & 0.044 & 1.627 \\
F4 - Subjective & 31.113 & 14.907 & 4.356 & 1 & 0.037 & 3.252 \\
F5 - Transference & 10.451 & 6.742 & 2.403 & 1 & 0.121 & 3.456 \\
Constant & -3.226 & 2.745 & 1.381 & 1 & 0.24 & 0.401 \\
\hline
\end{tabular}

Note. $B=$ regression coefficient; $S E=$ standard error; Wald = significance of the relationship between the independent variable and the logistic model criterion; $p=$ significance of the predictor; $O R=$ Odd Ratio. 
Table 7. Logistic regression model with interpretative factors as predictors of the IWRAD_IREF trend

\begin{tabular}{lcccccc}
\hline Factor & $\boldsymbol{B}$ & $\boldsymbol{S E}$ & Wald & $\boldsymbol{d f}$ & $\boldsymbol{P}$ & $\boldsymbol{O R}$ \\
\hline F1 - General models & -13.045 & 5.499 & 5.627 & 1 & 0.018 & 0.167 \\
F2 - Affective states & -1.058 & 9.945 & 0.011 & 1 & 0.915 & 0.347 \\
F3 - Situated & -32.725 & 11.158 & 8.602 & 1 & 0.003 & 0.235 \\
F4 - Subjective & -4.776 & 15.778 & 0.092 & 1 & 0.762 & 0.008 \\
F5 - Transference & -15.443 & 8.53 & 3.278 & 1 & 0.071 & 0.000 \\
Constant & 9.099 & 3.857 & 5.567 & 1 & 0.018 & 2.945 \\
\hline
\end{tabular}

Note. $\beta=$ regression coefficient; $S E=$ standard error; Wald: significance of the relationship between the independent variable and the logistic model criterion; $p=$ significance of the predictor, $O R=$ Odd Ratio. 


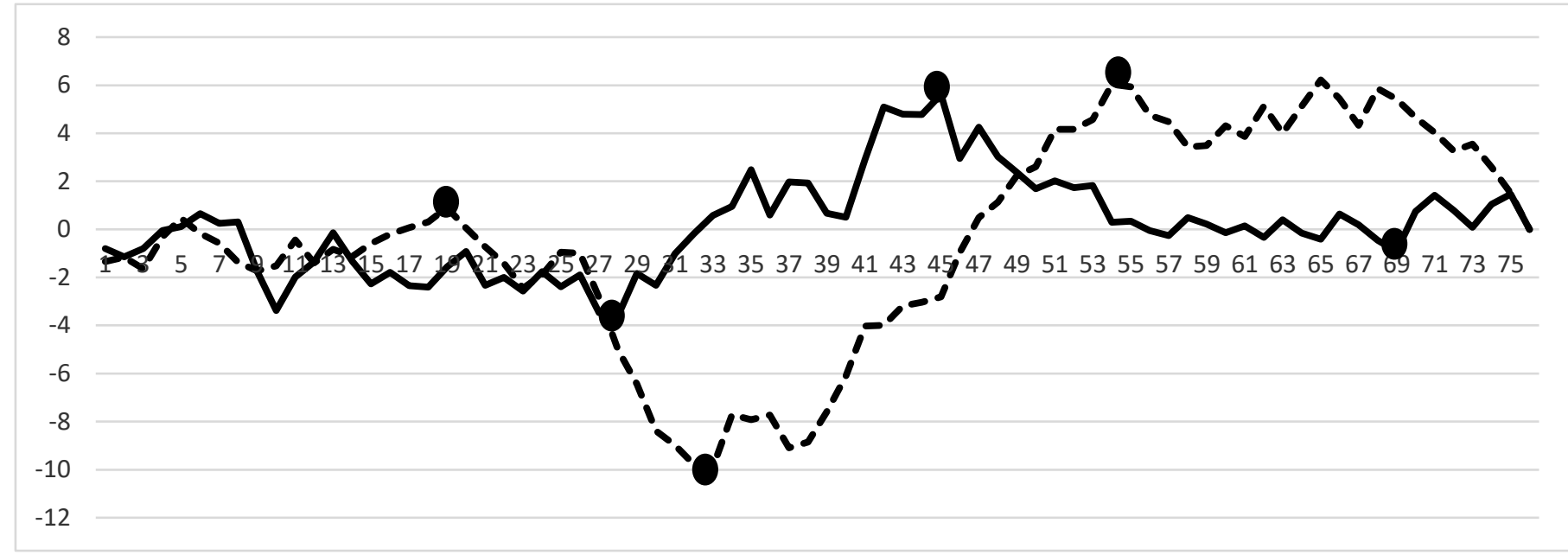

Figure 1. IWRAD_IWRRL and IWRAD_IREF trends detected in patient's clinical speech Note. Continuous line highlights the IWRAD_IREF trend and dotted line represents the IWRAD_IWRRL trend. Dots represent changing points defining trends. 


\begin{tabular}{|c|c|}
\hline Original Italian transcript & Translated version \\
\hline $\begin{array}{l}\text { Turn } 151 \text { P: [...] quando er } \\
\text { tipo alle medie, mi ricor } \\
\text { potevo arrabbiarmi con mi } \\
\text { fare rumore, sfogarmi, ed } \\
\text { cosa, una cosa opprimente } \\
\text { arrabbiavo anche io, però } \\
\text { mi arrabbiavo e quello ch } \\
\text { che mi mettevo in un ango } \\
\text { andavo in camera e l'arra } \\
\text { era andarsene, non fare p }\end{array}$ & $\begin{array}{l}\text { Turn } 151 \text { P: [...] when I was little, } \\
\text { like in secondary school, I remember } \\
\text { that I couldn't get angry at my } \\
\text { mother, make noise, let off steam, } \\
\text { and it was something, something } \\
\text { oppressive; I mean I got angry too, } \\
\text { but in the end I got angry and what } \\
\text { I did is I just sat in a corner and } \\
\text { I went to my room and me being angry } \\
\text { was leaving, not doing anything } \\
\text { else. }\end{array}$ \\
\hline $\begin{array}{l}\text { Turn } 152 \text { T: mh } \\
\text { simile a quello } \\
\text { moglie, quando } \\
\text { moglie si arrab. } \\
\text { ancora più chiu }\end{array}$ & $\begin{array}{l}\text { Turn } 152 \mathrm{~T} \text { : Hm ... this is very } \\
\text { similar to what happens with your } \\
\text { wife, when you get home your wife } \\
\text { gets angry and you become even more } \\
\text { reserved. }\end{array}$ \\
\hline $\begin{array}{l}\text { Turn } 153 \text { P: sì, sì } \\
\text { storia. }\end{array}$ & $\begin{array}{l}\text { arn } 153 \text { P: Yes, it's the same } \\
\text { ory. }\end{array}$ \\
\hline $\begin{array}{l}\text { Turn } 154 \text { T: per lei era } \\
\text { la sensazione che non a } \\
\text { veramente scelta, senti } \\
\text { arrabbiato ma non potev } \\
\text { si sentiva triste e arr } \\
\text { sapeva come esprimere q } \\
\text { provava. Non le rimanev } \\
\text { immobilizzarsi, in sile } \\
\text { tapparsi le orecchie e } \\
\text { sua madre, né la rabbia } \\
\text { riversava addosso ... E u } \\
\text { ricorda molto le discus } \\
\text { con sua moglie, non cre } \\
\text { lei arriva a casa, sua } \\
\text { lamenta, lei sente rabb } \\
\text { scatta in lei la necess } \\
\text { congelare le emozioni n }\end{array}$ & $\begin{array}{l}\text { Turn } 154 \text { T: For you it was, I would } \\
\text { say, the feeling of really having no } \\
\text { choice, you felt angry, but you } \\
\text { could not let off steam, you felt } \\
\text { sad and angry and you did not know } \\
\text { how to express what you were } \\
\text { feeling. All you could do was to } \\
\text { freeze, be silent, cover your ears } \\
\text { and not listen to your mother, nor } \\
\text { the anger that poured out of her... } \\
\text { This scene is very familiar to the } \\
\text { actual fight with your wife, don't } \\
\text { you think? When you get home, your } \\
\text { wife complains, you feel angry and } \\
\text { immediately rises the need to freeze } \\
\text { your emotions as an attempt not to } \\
\text { get even angrier... }\end{array}$ \\
\hline $\begin{array}{l}\text { urn } 155 \text { p: sì, si, si, sì, si, era } \\
\text { roprio un qualcosa proprio un ... un } \\
\text { solarmi, mia madre che si } \\
\text { rrabbiava, mi diceva qualcosa e io } \\
\text { i arrabbiavo, ed è vero, anche con } \\
\text { ia moglie accade che sento le } \\
\text { tesse cose, non ci avevo mai } \\
\text { ensato ma mi sento un po' come } \\
\text { lora, ha ragione ... e l'altro, } \\
\text { altro aspetto era mio padre che } \\
\text { on diceva mai niente, perché c'era } \\
\text { che questo, perché lui veramente } \\
\text { on diceva mai niente, stava in } \\
\text { ilenzio, non lo so, forse anche lui } \\
\text { ra molto simile a me, forse in }\end{array}$ & $\begin{array}{l}\text { really a... ar } \\
\text {, my mother us } \\
\text { used to say son } \\
\text { d to get angry, } \\
\text { with my wife } \\
\text { l the same thir } \\
\text { ht about it bu } \\
\text { ike at that tin } \\
\text { t and the other } \\
\text { hing, because } \\
\text { because he real }\end{array}$ \\
\hline
\end{tabular}


lui, non avrei mai pensato ma è proprio cosi about that but that's actually the way it is 